\title{
Stabilization of $\mathrm{Cd}$ and $\mathrm{Pb}$ in the contaminated soils by applying modified fly ash
}

\author{
Fuhao Liu ${ }^{1,2}$, Xunrong Huang ${ }^{1}$, Hanghang Zhao ${ }^{3}$, Xiongfei Hu${ }^{1}$, Lu Wang ${ }^{1}$, Xin Zhao ${ }^{1}$, Pengcheng Gao ${ }^{1,4}$, \\ Puhui $\mathrm{Ji}^{1,5}$, $^{*}$
}

1 College of Natural Resources and Environment, Northwest A\&F University, Yangling 712100, China

2 Key Laboratory of Original Agro-Environmental Pollution Prevention and Control, Ministry of Agriculture/Tianjin Key Laboratory of Agro-environment and Safe-product, Tianjin 300191, China

3 School of Water and Environment, Chang'an University, Xi'an 710054, China

4 Scientific Laboratory of Heyang Agricultural Environment and FarmLand Cultivation, Ministry of Agriculture and Rural Affairs, Weinan 714000, China

5 Key Laboratory of Pollution Ecology and Environmental Engineering, Institute of Applied Ecology, Chinese Academy of Sciences, Shenyang 110016, China

\section{H I G H L I G H T S}

- After modification, the adsorption capacity of fly ash on heavy metals is enhanced.

- Modified fly ash has significant effect on stabilization of Cadmium and lead.

- The activity of heavy metals stabilized after 6 months of operation of the column.

- DOC, pH, and organic matter play an important role in heavy metal remediation.

\section{ARTICLE INFO}

Article history:

Received November 9, 2020

Revised December 15, 2020

Accepted January 1, 2021

Keywords:

Cadmium

Lead

Modified fly ash

Stabilization

Leaching
GRAPHICAL ABSTRACT

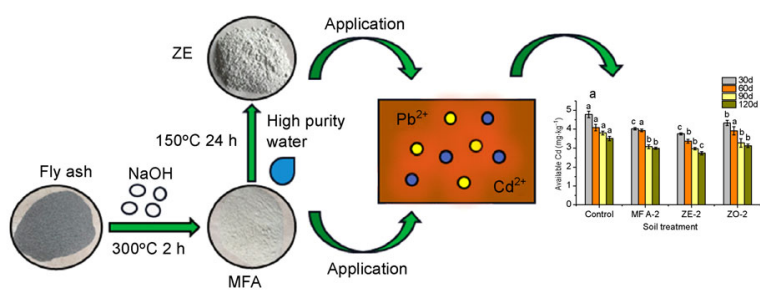

A B S T R A C T

This study investigated the stabilization of heavy metals by adding modified fly ash (FA) to contaminated soils, and two similar materials, $\mathrm{NaOH}$-zeolite (ZE) and natural zeolite (ZO) were introduced into the soils for comparison. Column leaching tests were conducted to analyze the difference of stabilization effects between the three materials. Leaching columns were run for 6 months, and a considerable stabilization of heavy metals in the soils was observed. The concentration of cadmium $(\mathrm{Cd})$ and lead $(\mathrm{Pb})$ in the amended soil substantially decreased $(p<0.05)$. The results indicated that after 11 weeks of column leaching, $\mathrm{Cd}$ and $\mathrm{Pb}$ concentrations in the soil leachate decreased to below the detection limit due to amendment stabilization. Among the three amendments, the ZE amendment showed the optimum capacity for heavy metal immobilisation in the soils. In addition, after 6 months of leaching, $\mathrm{Pb}$ and $\mathrm{Cd}$ concentrations in the soils with the three different amendments decreased to various degrees. The amendments of modified FA and ZE were better than those of natural ZO. Coal FA, after modification, is a useful amendment for the remediation of heavy metals in the contaminated soil.

\footnotetext{
* Corresponding author

E-mail address: jipuhui1983@nwsuaf.edu.cn (P. Ji)
}

\section{Introduction}

Soil heavy metal pollution is one of the most serious global environmental problems (Zhao et al., 2015; Huang et al., 
2016). Most heavy metals in contaminated soils have been introduced through metal smelting or the release of metal ions in agricultural fields over decades or even centuries (Shao et al., 2016; Alicja et al., 2018). This contamination adversely affects not only plant growth but also human health through food chains (Mukherjee et al., 2020). Among these contaminants, $\mathrm{Cd}$ and $\mathrm{Pb}$ present the most serious environmental hazards. Rice has a strong enrichment effect on Cd. Ingesting contaminated rice is likely to cause severe chronic celiac disease, poisoning, renal insufficiency, osteoporosis, cancer, and other symptoms (Xu et al., 2020). Pb is one of the most toxic heavy metals that pose a direct threat to organisms. $\mathrm{Pb}$ cannot be degraded through microbial activities or chemical reactions (Zeng et al., 2017).

The soil environment complexity leads to the difficulty of heavy metal control. Studies (Xu et al., 2006; Fest et al., 2008) have shown that some physical and chemical properties of soil, such as $\mathrm{pH}$, DOC, organic matter, redox potential, carbonate content, and cation exchange capacity, directly or indirectly affect the migration behavior of heavy metals. However, if heavy metals are bound with inactive compounds, their toxicity and mobility are decreased (Houben et al., 2012) and their hazards to the environment is minimised. The in situ stabilization of heavy metals has been reported (Pani and Singh, 2019; Wang et al., 2021). The purpose of this technique is to reduce metal activities by using soil amendments to immobilise metals. The stabilization technology has a wide application in many studies. Sneddon et al. (2006) showed that bone-meal amendment substantially reduced the release of $\mathrm{Pb}, \mathrm{Cd}$, and $\mathrm{Zn}$ in the soil leachate. Simultaneously, the exchangeable amount of $\mathrm{Zn}, \mathrm{Pb}, \mathrm{Cu}$, and $\mathrm{Cd}$ in the polluted soil evidently decreases when hydroxyapatite is added (Li et al., 2020; Nag et al., 2020).

Coal fly ash (FA), as an industrial by-product, was widely used in soil heavy metals stabilization. FA primarily comprises silica and alumina (Leelarungroj et al., 2018). Due to its large bulk density, particle size, porosity, and specific surface area, FA is suitable to be used as an adsorbent (Ahmaruzzaman, 2010). A study reported that FA can reduce the heavy metal bioavailability in soils due to its surface functionalisation and complexation. (Lee et al., 2006). Although FA has been applied to stabilize heavy metals in most cases, most stabilization measures only use raw ash (Lee et al., 2008; Nayak et al., 2015). Due to the limited adsorption capacity of raw ash toward heavy metal ions, some researchers have explored many physical and chemical methods to stimulate the adsorption potential of FA (Wu et al., 2012; Deng et al., 2018; Qi et al., 2019). The modified FA has been widely used, but most of its applications are limited to adsorbing heavy metal ions in the waste-water environment (Astuti et al., 2017; Huang et al., 2020b). Limited studies have focused on the application of modified FA to soils as a heavy metal amendment. In this study, column leaching tests were performed and the immobilising effect of FA-based modified materials was investigated, which may provide useful information for low-cost heavy metal removal.

Moreover, alkali $(\mathrm{NaOH})$ was used as an activator, and a low-temperature roasting method was introduced. $\mathrm{NaOH}$ zeolite (ZE) was synthesized from FA by using two-step hydrothermal roasting. This study determined the capacity of modified FA on metal-polluted soils and explored the leaching effect and mechanism of soil $\mathrm{pH}$, dissolved organic carbon (DOC), and soil organic matter (SOM) on $\mathrm{Cd}$ and $\mathrm{Pb}$. Moreover, we explored whether the performance of the modified FA is better than that of similar materials.

\section{Materials and methods}

\subsection{Soils}

The soil samples were collected at a depth of $0-20 \mathrm{~cm}$ from the campus of the Shaanxi University of Technology in Hanzhong, Shaanxi $\left(33^{\circ} 07^{\prime} \mathrm{N}, 107^{\circ} 05^{\prime} \mathrm{E}\right)$. This sampling site was selected because the Hanzhong area was polluted with heavy metals throughout the year. The soil samples were air-dried and sieved through a coarse sieve (size $<2 \mathrm{~mm}$ ) to remove impurities such as stones. However, a certain amount of $\mathrm{Cd}$ and $\mathrm{Pb}$ were added to the collected soils to increase metal concentrations to a set level. The available $\mathrm{Cd}$ and $\mathrm{Pb}$ concentration after manual configuration was 5.06 and $515 \mathrm{mg} \mathrm{kg}^{-1}$, respectively. Table 1 presents the soil properties. The soils were sieved through a $1-\mathrm{mm}$ sieve and stored in polyethylene bags.

\subsection{Amendment preparation}

Coal FA, a product of coal combustion, was obtained from Datong Thermal Power Plant. Coal FA was oven-dried at $105^{\circ} \mathrm{C}$ for $3 \mathrm{~h}$; the dried FA was passed through a $0.3-\mathrm{mm}$ mesh sieve and then was completely mixed with $\mathrm{NaOH}$ (powder) in the 5:8 ratio. The resultant mixture was calcined in a nickel crucible for $3 \mathrm{~h}$ at $300^{\circ} \mathrm{C}$, and the sample was

Table 1 Basic physical and chemical properties of soils and materials.

\begin{tabular}{ccccccccc}
\hline & $\mathrm{pH}$ & $\mathrm{SOM}\left(\mathrm{g} \mathrm{kg}^{-1}\right)$ & $\mathrm{Cd}\left(\mathrm{mg} \mathrm{kg}^{-1}\right)$ & $\mathrm{Pb}\left(\mathrm{mg} \mathrm{kg}^{-1}\right)$ & $\mathrm{Zn}\left(\mathrm{mg} \mathrm{kg}^{-1}\right)$ & $\mathrm{Cu}\left(\mathrm{mg} \mathrm{kg}^{-1}\right)$ & $\mathrm{Mn}\left(\mathrm{mg} \mathrm{kg}^{-1}\right)$ & $\left.\mathrm{Fe}_{\left(\mathrm{mg} \mathrm{kg}^{-1}\right.}\right)$ \\
\hline Soil & 8.11 & 32.1 & 5.06 & 515 & 134 & 47 & 597 & 18600 \\
FA & 7.81 & 2.57 & 0.52 & 47.7 & 58.7 & 46.3 & 153 & 16500 \\
MFA & 8.14 & - & 0.37 & 2.37 & 39.6 & 40 & 131 & 13500 \\
ZE & 8.86 & - & 0.31 & 3.82 & 25.3 & 34.5 & 90 & 9220 \\
ZO & 7.95 & - & 0.40 & 8.20 & 45.8 & 0.36 & 62.7 & 5020 \\
\hline
\end{tabular}


naturally cooled to normal atmospheric temperature after the reaction. Finally, the sample was washed with deionised water until $\mathrm{pH}$ stabilized and was dried to obtain $\mathrm{NaOH}$-modified FA (MFA) at $105^{\circ} \mathrm{C}$ for $4 \mathrm{~h}$. Subsequently, MFA and high-purity water were mixed in the ratio of 1:6 in a high-pressure reactor at $150^{\circ} \mathrm{C}$ for $24 \mathrm{~h}$. Similarly, the samples were washed with deionised water until $\mathrm{pH}$ stabilized to acquire $\mathrm{ZE}$. The third amendment was natural zeolite ( $Z O)$ purchased from a material market (AR) and originated from Gongyi City, Henan Province. Table 1 presents the basic characteristics of the amendments. The micromorphology and chemical elements of amendments were investigated using field scanning electron microscopy (SEM, S-4800, Hitachi Limited, Japan).

\subsection{Leaching column set-up}

Figure 1 illustrates the scheme of the leaching column set-up. The outer diameter and height of the Polyvinyl chloride (PVC) columns designed were 10 and $30 \mathrm{~cm}$. The column was divided into three layers, and one sampling port was set at each $10 \mathrm{~cm}$. A polyamide mesh (size $50 \mu \mathrm{m}$ ) was placed at the bottom of the column, and $2 \mathrm{~cm}$ of the quartz sand (size $<0.5$ $\mathrm{mm}$ ) was filled for leachate filtration. The lowest end of the column was connected to a funnel to collect the leachate, and a stopcock was placed on the funnel to adjust the flow from the column. $1 \mathrm{~cm}$ of the quartz sand was filled at each sampling port, and remaining space inside the column was filled with the soil samples (size $<1 \mathrm{~mm}$ ). Similarly, the top of the column was filled with $2 \mathrm{~cm}$ of quartz sand (size $<0.5 \mathrm{~mm}$ ) to ensure that no soil was lost during leaching.

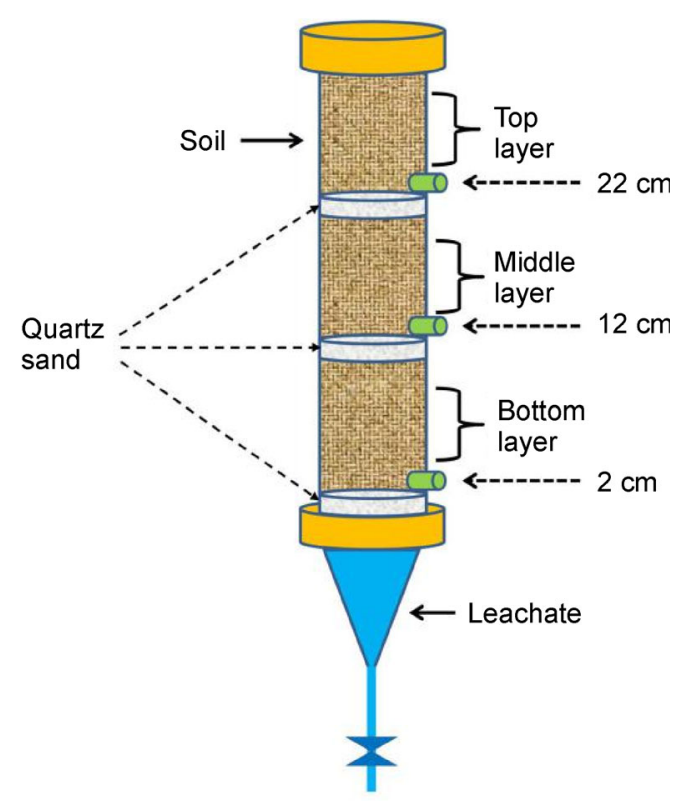

Fig. 1 Schematic view of leaching column.

\subsection{Column experiments}

MFA, ZE, ZO, and the tested soils were thoroughly mixed together to ensure homogeneity. Approximately $1800 \mathrm{~g}$ of the air-dried soil was added to each column Three amendments of $0.5 \%, 1 \%$, and $2 \%(\mathrm{w} / \mathrm{w})$ were prepared. Each treatment $(0.5 \%, 1 \%$ or $2 \%)$ was performed in 3 replicates, and as control, the untreated soil sample treatment was conducted in three replicates. Before irrigation, the columns were equilibrated at $25^{\circ} \mathrm{C}$ and $60 \%$ water-holding capacity was maintained for 5 weeks. After the equilibrium period, the columns were irrigated with deionised water at a flow rate of $200 \mathrm{~mL}$ per week, and the leachate and soil samples were collected weekly and monthly.

\subsection{Chemical analysis}

\subsubsection{Leachate analyses}

After each leachate collection, the solution volume was measured with a graduated cylinder. The $\mathrm{pH}$ of the solution was simultaneously determined using a $\mathrm{pH}$ meter. Subsequently, the leachate was filtered with a $0.45-\mu \mathrm{m}$ membrane, and then each solution sample was divided into two subsamples. One of these subsamples was used to measure DOC by using a total organic carbon analyzer (Shimadzu TOC-L CPH), and the other sample was used to determine the $\mathrm{Pb}$ and $\mathrm{Cd}$ concentrations of the leachate by using a Graphite furnace atomic absorption spectrometer (PinAAcle 900H).

\subsubsection{Soil analyses}

The collected soil samples were divided into two subsamples; the first subsample was temporarily stored in an ultra-lowtemperature refrigerator, and the other subsample was airdried in a drying room. The soils were sieved through a $0.15-$ $\mathrm{mm}$ mesh and kept in polyethylene bags after crushing. Potassium dichromate oxidation was conducted to measure the organic matter content in soils. The total amount of $\mathrm{Cd}, \mathrm{Pb}$, $\mathrm{Cu}, \mathrm{Zn}, \mathrm{Fe}$, and $\mathrm{Mn}$ was digested with triacid $\left(\mathrm{HNO}_{3}, \mathrm{HClO}_{4}\right.$, and $\mathrm{HF}$ ). The available heavy metals were extracted using the M3 method, the solution analyzed using flame atomic absorption spectroscopy (PinAAcle 900H).

\section{Results and discussion}

\subsection{Amendment characterization}

Figure 2A-C present the SEM images of FA, MFA, and ZE. FA reacted and fused with alkaline substances (Fig. 2B), which promoted the dissolution of an amorphous glass phase in FA, and the surface of the spherical glass phase became extremely rough and irregular agglomerates, with a highly increased specific surface area and microporous structure, were formed, which resulted in an increase in adsorption capacity of FA for heavy metals. Under alkaline hydrothermal 
conditions, the sample exhibited a basic ZO structure, and FA dissolved in the alkaline solution (Fig. 2C), so that the siliconoxygen and aluminum-oxygen bonds were broken and reorganised in the presence of an alkaline catalyst, indicating that geo-polymerisation reactions were involved in modification (Jaarsveld et al., 1999). Terzano et al. (2005) observed that geo-polymerisation can deactivate heavy metals in the solid phase, and under these conditions, heavy metals can lose certain mobilisation capacity through adsorption and precipitation or by chemical bonding with amorphous.

\subsection{Analysis of components in the soil leachate}

\subsection{1 $\mathrm{pH}$ in the soil leachate}

Figure $3 \mathrm{~A}-\mathrm{C}$ present the leachate $\mathrm{pH}$ profile. Compared with control, the $\mathrm{pH}$ of the leachate with ZE and MFA amendments was considerably higher and increased with an increase in the rate of amendment application (Fig. 3 A and B). Mainly because FA absorbed a large amount of sodium hydroxide during modification and bonded with it; hence, numerous
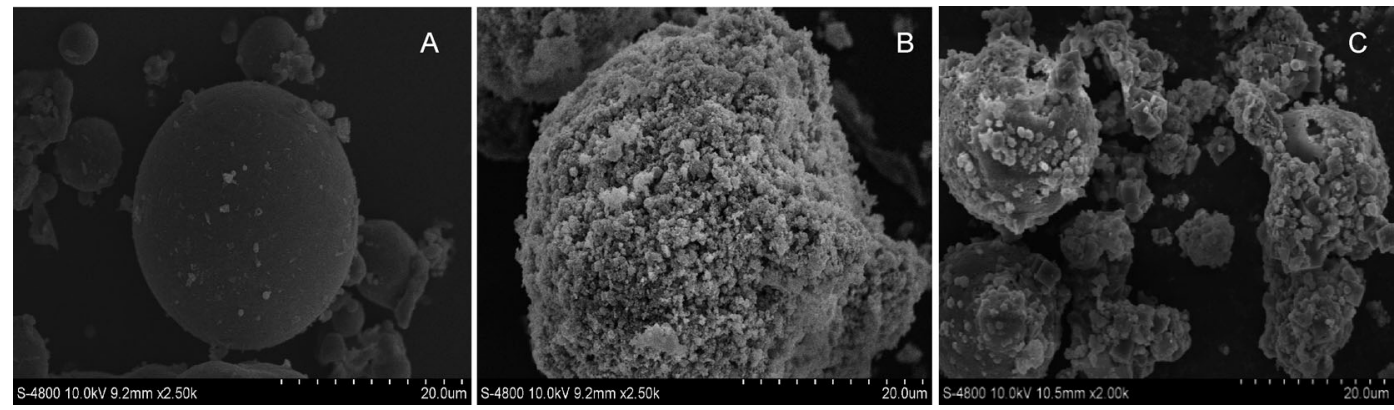

Fig. 2 SEM images of FA (A), MFA (B), and ZE (C).
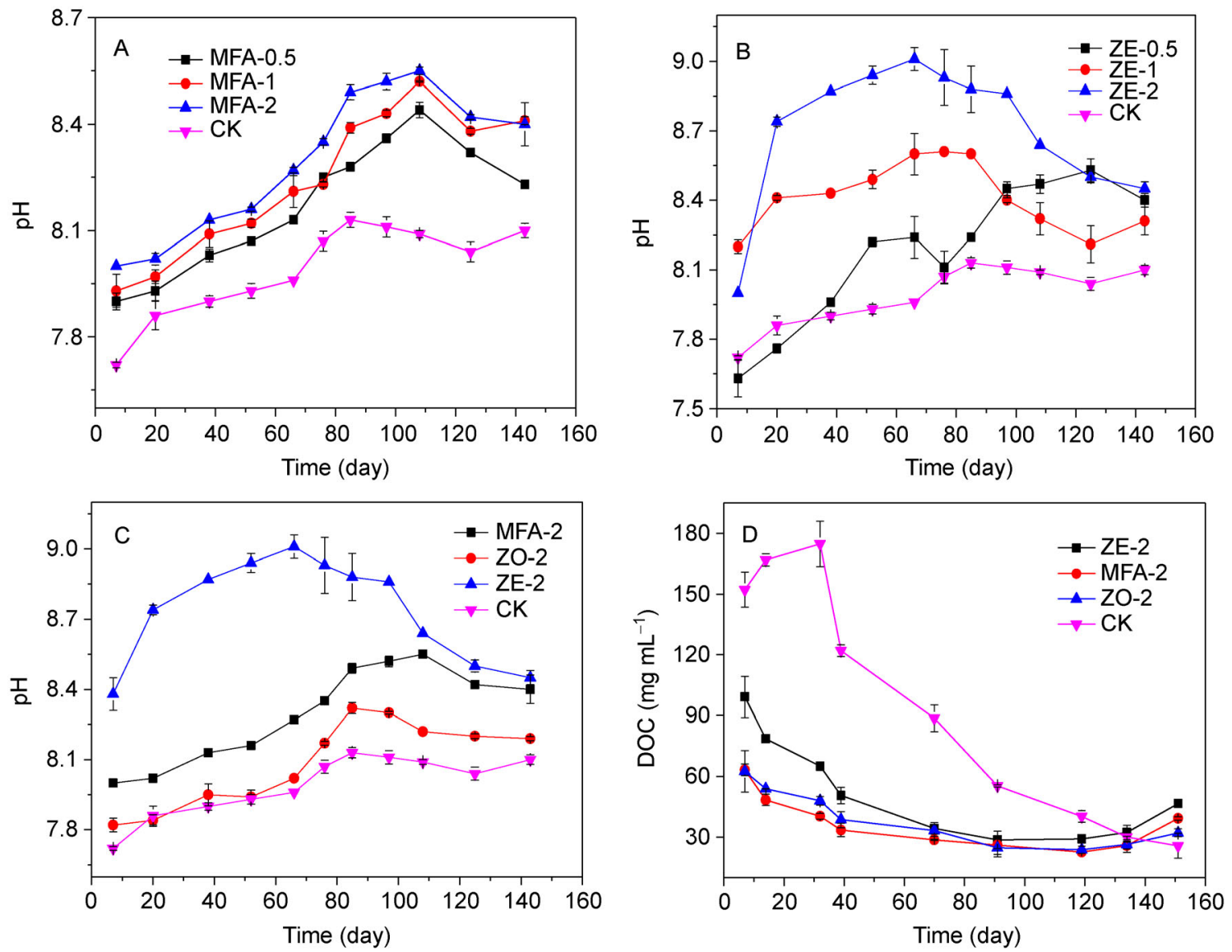

Fig. 3 Soil column $\mathrm{pH}$ of the leachate with different amendments and gradient (A-C), and the concentrations of DOC (D). MFA$x$, ZE- $x$, ZO- $x$ indicates that the amount of amendments is $x \%$ of the soil weight. Error bars represent a standard deviation on either side of the mean. 
hydroxide ions were released into the soil medium, neutralising most hydrogen ions present in the original soil solution. Furthermore, this result might be contributed to the available surface negative charges of amendments and amendment addition, which led to and increase in the negative charges at the edges of clay particles and change in the soil acidity to alkaline. This behavior was beneficial to the metallic ions adsorbed on the active sites of amendments for reducing the mobility of metal ions. When the treatments of $2 \%$ MFA and ZE were performed, $\mathrm{pH}$ increased by 0.65 and 1.25 , respectively. The treatment of $2 \% \mathrm{ZO}$ showed no considerable statistical significance in $\mathrm{pH}$ change, which indicated that $\mathrm{ZE}$ and MFA exhibited a greater effect than $\mathrm{ZO}$ on soil $\mathrm{pH}$. $\mathrm{pH}$ for the soil leachate with MFA and ZE amendments reached the peak in 15 and 8 weeks, respectively, indicating the ZE amendment had stronger effect on $\mathrm{pH}$ than the MFA amendment. After the peak, the effect of these amendments on $\mathrm{pH}$ decreased and then became stable. A speculation is that alkaline substances leached continually to a low level. Additionally, the soil played an important role as a buffer through the ion exchange process of colloids to subsequently stabilize $\mathrm{pH}$.

\subsubsection{DOC in the leachate}

Figure 3D presents the DOC concentrations. Compared with the control profiles, DOC profiles crucially decreased with the addition of the three amendments. The results indicated that when three $2 \%$ amendments were added, MFA provided the optimal control on DOC and DOC leached from the ZE-added soil primarily because after FA reacted with $\mathrm{NaOH}$, the glass phase on the sample surface was dissolved by an alkaline attack to form irregular agglomerate structures (Fig. 2B-C); thus, the specific surface area increased, which ultimately improved the adsorption and fixation of DOC in the soil solution. Another study showed that the DOC amount in the leachate increased at higher $\mathrm{pH}$ (Christ and David, 1996); the
DOC concentration of the ZE treatment was higher than that of MFA treatment. DOC concentrations decreased considerably in the initial stage of the experiment, indicating that amendment application increased the stabilization effect on DOC. DOC comprises various low-molecular-weight organic compounds such as mono fatty acids, amino acids, and sugar acids (Antoniadis and Alloway, 2002). By contrast, some studies (Brunner and Blaser, 1989; Christ and David, 1996) have shown that an increase in $\mathrm{pH}$ leads to an increase in DOC solubility. However, the phenomenon presented in this study indicated that soil amendments have a greater impact on DOC than $\mathrm{pH}$. Moreover, DOC solubility depends on many factors, such as the size of organic molecules, $\mathrm{pH}$, charge density, and cation concentration (Andersson et al., 2000). After 10 weeks, with the continuous leaching of deionised water, DOC concentrations finally stabilized (Fig. 3D) most likely due to amendment consumption and the strong buffering capacity of the soil (Sneddon et al., 2006). Furthermore, a lack of input of organics may lead to a limited carbon source into the leachate (Andersson et al., 2000). After approximately 20 weeks, the DOC concentration slightly increased, indicating that in addition to $\mathrm{pH}$ and the stabilization capacities of amendments, other factors influenced DOC solubility. We inferred that it may be a function of microbial activities; microorganism apoptosis can lead to the release of soluble carbon and nitrogen (Morel et al., 2009), resulting in an increase in the DOC concentration.

\subsubsection{The $\mathrm{Pb}$ and $\mathrm{Cd}$ dissolved in the leachate}

Figure 4A and $\mathrm{B}$ shows the concentrations of $\mathrm{Cd}$ and $\mathrm{Pb}$ dissolved in the leachate. Compared with the control, when $2 \%$ ZE amendment was used, the concentrations of dissolved Cd leaching from soil were the lowest (Fig. 4A), and for the $2 \%$ MFA treatment, this concentration was slightly higher than that for the ZE treatment, which might be attributed to the effect of higher $\mathrm{pH}$. Some studies have shown that $\mathrm{pH}$ plays an
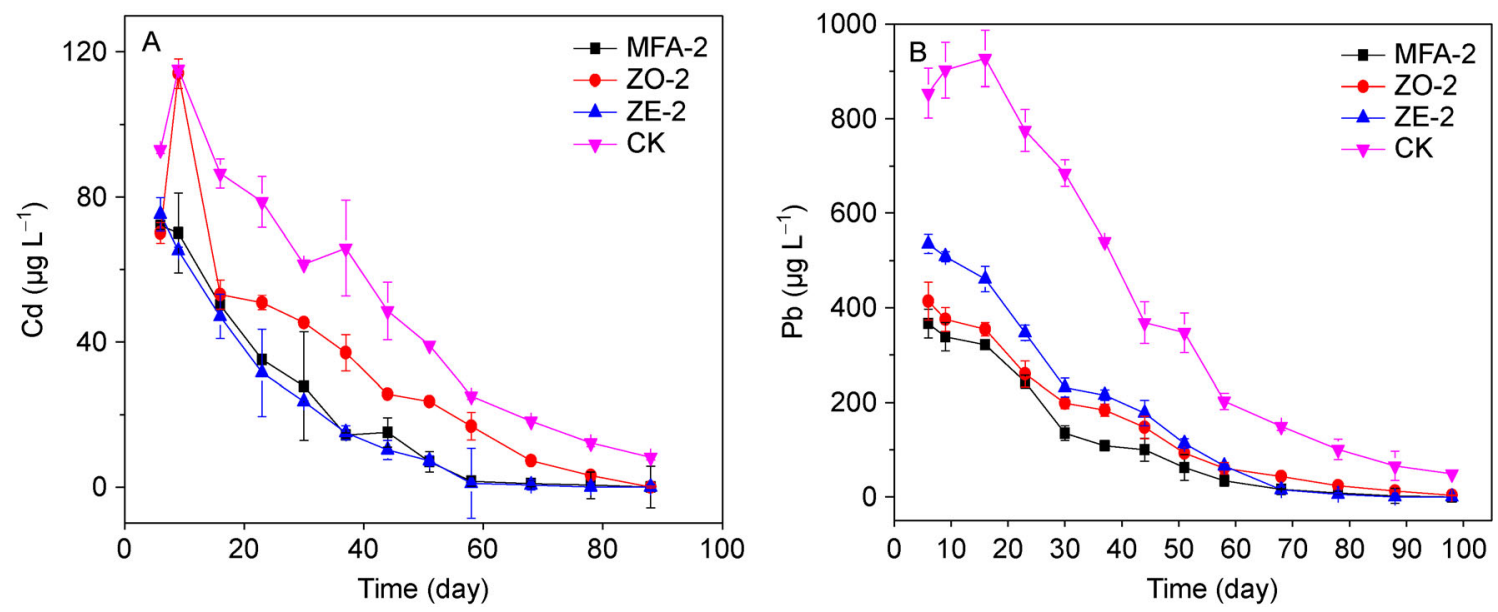

Fig. 4 Concentrations of dissolved $\mathrm{Cd}(\mathrm{A})$ and $\mathrm{Pb}(\mathrm{B})$ in the leachate. Error bars represent a standard deviation on either side of the mean. 
important role in heavy metal stabilization and dissolution (Smolyakov et al., 2010; Huang et al., 2017). Another study (Bradl, 2004) showed that an increase in the $\mathrm{pH}$ value induces heavy metal stabilization through several processes in soil, including the increased precipitation of heavy metals in the soil environment. For example, $\mathrm{Cd}$ ions precipitate in the $\mathrm{Cd}(\mathrm{OH})_{2}$ form. In addition, FA mainly comprises $\mathrm{Al}_{2} \mathrm{O}_{3}$ - and $\mathrm{SiO}_{2}$-related compounds. Si available in MFA was dissolved, and the dissolved silicate ions combined with acid exchange component $\mathrm{Cd}$ to form insoluble cadmium silicon and metal silicate cadmium. Moreover, the tetrahedron of aluminum oxides formed through $\mathrm{Al}$ and $\mathrm{O}$ elements combined a part of Cd ions (Lin et al., 2019). Therefore, the concentration of dissolved $\mathrm{Cd}$ in the leachate highly decreased. By the end of week 9, dissolved $\mathrm{Cd}$ in the soil with MFA and ZE amendments continued to decrease to below the detection limit, and dissolved $\mathrm{Cd}$ in the soil with the $\mathrm{ZO}$ amendment remained at detectable level. On one hand, the amount of soluble heavy metals was relatively small in the overall amount of heavy metals. By contrast, only a small amount of heavy metals dissolved in the amended soil, and their concentrations became relatively stable after long-term leaching. In summary, MFA and ZE have a high capacity for Cd stabilization.

Figure 4B presents the concentration profiles of $\mathrm{Pb}$ dissolved in the leachate.The $\mathrm{Pb}$ concentration shows a trend similar to The dissolved $\mathrm{Cd}$ concentration with the application of the three amendments, and the $\mathrm{Pb}$ concentration substantially decreased when the soil was treated with $2 \%$ of the amendments. The MFA $2 \%$ treatment, which led to heavy metal stabilization mainly due to an increase in the specific surface area of FA under alkaline modification conditions, was the most effective. The specific surface area of FA and MFA was $1.45 \mathrm{~cm}^{2} \mathrm{~g}^{-1}$ and $31.6 \mathrm{~m}^{2} \mathrm{~g}^{-1}$, respectively; this finding was reported in our previous study (Huang et al., 2020a). However, under the ZE treatment condition, dissolved $\mathrm{Pb}$ and $\mathrm{Cd}$ showed a different trend
(Fig. 4). Titeux and Delvaux (2009) reported that DOC and Pb can form a strong complex, and therefore the increase in the $\mathrm{Pb}$ concentration in the leachate may be resulted from the higher DOC concentration with the ZE amendment. Table 2 presents a strong positive Pearson's correlation coefficient ( $r=0.94, p<0.001$ ) between dissolved $\mathrm{Pb}$ and $\mathrm{DOC}$ concentrations. Furthermore, under the action of amendments, some $\mathrm{Pb}$ ions existed in the form of $\mathrm{Pb}(\mathrm{OH})_{2}$, an amphoteric compound, and in a certain $\mathrm{pH}$ range, their solubility increased with the increase in $\mathrm{pH}$, which can explain the increase in dissolved $\mathrm{Pb}$ when the $\mathrm{ZE}$ amendment was applied to the soil. Moreover, during the 11th week of the experiment, the dissolved $\mathrm{Pb}$ level decreased to below the detection limit due to the reason similar to the $\mathrm{Cd}$ level decrease below the detection limit. Another reason for this phenomenon could be that the dissolved $\mathrm{Pb}$ concentration was correlated to the DOC concentration, which must be investigated in the future.

Table 2 Pearson's correlation coefficients $r$ between dissolved $\mathrm{Pb}$ and $\mathrm{Cd}$ and DOC concentration and $\mathrm{pH}$ in leachates $(n=140)$.

\begin{tabular}{lllll}
\hline & $\mathrm{Cd}$ & $\mathrm{Pb}$ & $\mathrm{DOC}$ & $\mathrm{pH}$ \\
\hline $\mathrm{Cd}$ & 1 & $0.93^{\star \star \star}$ & $0.78^{* \star *}$ & $-0.57^{* \star}$ \\
$\mathrm{Pb}$ & $0.93^{* \star *}$ & 1 & $0.94^{* \star *}$ & $-0.45^{\star}$ \\
\hline
\end{tabular}

${ }^{* \star *} p<0.001 .{ }^{* *} p<0.01 .{ }^{*} p<0.05$.

3.3 Profiles of $\mathrm{Cd}, \mathrm{Pb}$, and soil organic matter in the soil matrix

\subsubsection{Bioavailability of $\mathrm{Cd}$ and $\mathrm{Pb}$}

The bioavailable (available) heavy metals are the fraction of those easily absorbed by plants in soils and are the most harmful to the soils (Semple et al., 2004). Compared with the control, the available $\mathrm{Cd}$ (Fig. 5A and B) was considerably decreased in the amended soil, which suggested that
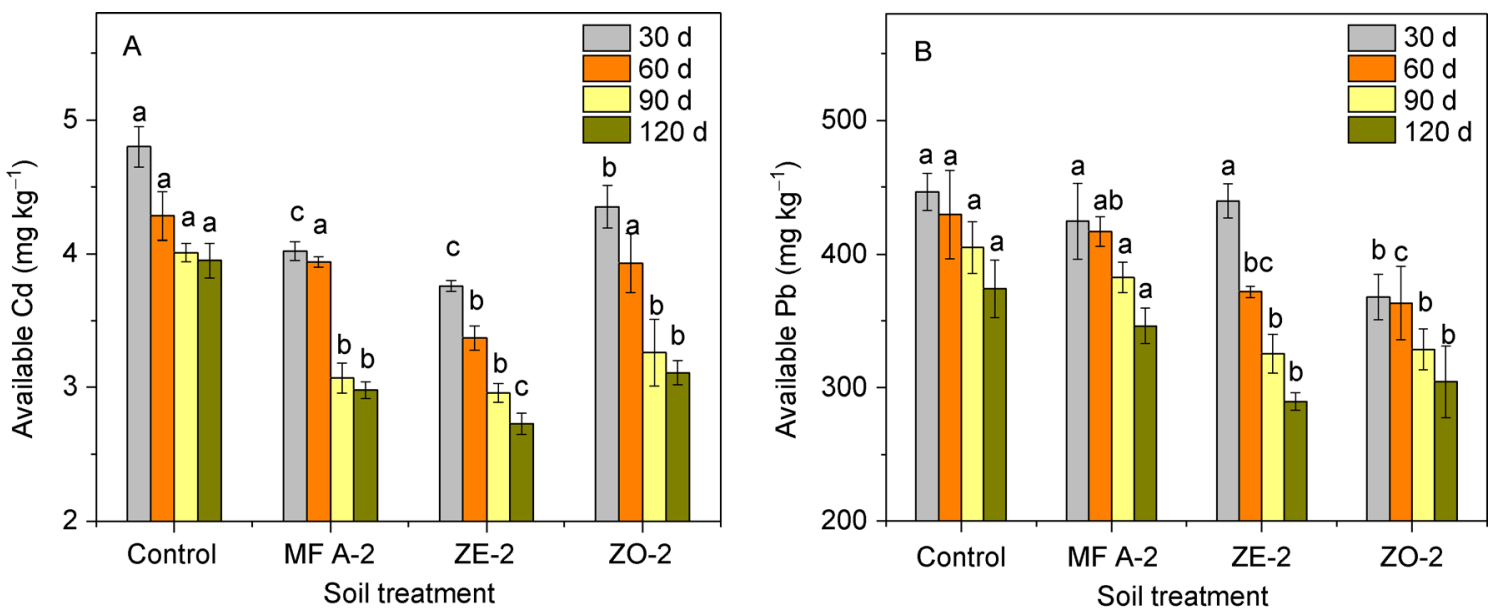

Fig. 5 Concentrations of available $\mathrm{Cd}(\mathrm{A})$ and $\mathrm{Pb}(\mathrm{B})$ in the soil column in different time periods with the addition of the three different amendments. MFA-2, ZE-2, and ZO-2 indicate that the amount of amendments is $2 \%$ of the soil weight. The data are the average of the three columns, the error bars represent a standard deviation on either side of the mean. Different lower-case letters indicate significant differences among treatments at $p<0.05$. 
deionised water transferred a small amount of heavy metals into the leachate. In addition, the application of the amendments led to a decrease in the mobility of heavy metals. Adsorption and precipitation play an important role in controlling $\mathrm{Cd}$ levels in the contaminated soils (Bradl., 2004). Compared with the ZO $2 \%$ treatment, MFA $2 \%$ and ZE $2 \%$ treatments showed a higher capacity to immobilise $\mathrm{Cd}$, which can be explained by the fact that $\mathrm{NaOH}$-modified FA comprised more alumino silicates and most particles showed a porous honeycomb structure with a large specific surface area (Fig. 2C). Studies have shown that the adsorption capacity for heavy metals is positively related to the specific surface area of adsorbents (Stötzel et al., 2009), which indicated soil amendments adsorbed the inorganic pollutants present in the soil well and therefore reduced the mobility and biological toxicity of $\mathrm{Cd}$. In conclusion, MFA and ZE amendments have an effective immobilisation effect on $\mathrm{Cd}$ in the soil.

The ZE amendment reduced Cd uptake in the soil more effectively than the MFA amendment (Fig. 5A). Numerous researchers have reported soil $\mathrm{pH}$ as the most important factor that affects the metal solution and soil surface chemistry (Bradl., 2004; Zeng et al., 2011). The absorption capacity for various heavy metals on the solid phase of the soil was enhanced by increasing the $\mathrm{pH}$ value. The $\mathrm{pH}$ of the $\mathrm{ZE} 2 \%$ treatment was 0.45 higher than that of the MFA $2 \%$ treatment (Fig. 2C), which is consistent with the finding that when $\mathrm{pH}$ increases by approximately 0.5 , the soil's capacity to adsorb Cd becomes twice (Khan et al., 2008). Furthermore, an increase in $\mathrm{pH}$ in the soil causes metal fixation through several processes: numerous anions are adsorbed on heavy metal surfaces or heavy metals are precipitated in the form of oxides, hydroxides, carbonates, and phosphates (Houben et al., 2012). Compared with the ZE amendment, MFA and ZO amendments did not evidently affect the Cd concentration in the first two months may be because the effect of $\mathrm{pH}$ on these two amendments in the initial stage was moderated due to the soil buffering effect (Duan et al., 2018). However, under the ZE amendment, $\mathrm{pH}$ increased sharply at the beginning of the experiment and remained stable for a long time, which led to a decrease in Cd mobilisation. Moreover, SEM images showed that ZE has porous aluminosilicate crystals to form a framework structure and a rougher surface than MFA does, indicating that ZE has high capacity to adsorb $\mathrm{Cd}$ ions. Furthermore, high $\mathrm{pH}$ affects the concentration of inorganic carbon and leads to carbonate buffering, which results in the formation of carbonate precipitates, complexes, and secondary minerals with heavy metals (Basta and McGowen, 2004). Raw FA contains a large amount of silicon, which can substantially increase silicon available in the soil that combines with $\mathrm{Cd}$ to form compounds and thus Cd mobility decreases. Studies have shown that the introduction of silicon improves soil attributes (Ahmaruzzaman, 2010). Our results indicated that $\mathrm{NaOH}$-modified FA highly immobilised $\mathrm{Cd}$ in the contaminated soil.
Compared with the control, available $\mathrm{Pb}$ amounts significantly decreased when the three amendments were added (Fig. 5B). The ZE 2\% treatment led to a drastic decrease in the available $\mathrm{Pb}$ concentration, which can be attributed to combined action of $\mathrm{pH}$ and amendments. Griffin and $\mathrm{Au}$ (1977) showed that $\mathrm{Pb}$ can be hydrolysed at low $\mathrm{pH}$ and can undergo multiple hydrolysis reactions where $\mathrm{Pb}(\mathrm{OH})_{2}$ is the main form when $\mathrm{pH}$ is $>9$ and $\mathrm{Pb}(\mathrm{OH})^{+}$mainly exists in $\mathrm{pH}$ of 6-10 (Tian et al., 2018). High $\mathrm{pH}$ with the ZE amendment leads to small metal solubility or highly stable metal compound precipitates, which may be an important reason for the decrease in the $\mathrm{Pb}$ concentration. The microporous structure of $\mathrm{ZE}$ has a strong capacity for $\mathrm{Pb}$ adsorption; its pore volume can reach approximately $50 \%$, and the pore size of ions is obviously larger than the hydration radius of lead ions, which enhances the adsorption capacity of $\mathrm{Pb}$. Additionally, the special physical structure of ZE provided it a strong ion exchange capacity: $\mathrm{Si}^{4+}$ in $\mathrm{ZE}$ was replaced with $\mathrm{Al}^{3+}$, resulting in excessive negative charges, for which monovalent or divalent cations $\left(\mathrm{Na}^{+}, \mathrm{K}^{+}, \mathrm{Ca}^{2+}\right.$, and $\mathrm{Mg}^{2+}$ ) compensated. Because these cations were exchangeable in the soil environment, they can be replaced with $\mathrm{H}^{+}, \mathrm{H}^{+}$, and $\mathrm{Pb}^{2+}$ in the soil, and consequently, the heavy metal ions can be immobilised. In the final stage of the column experiment, no considerable change was observed in the $\mathrm{Pb}$ concentration with the addition of three different amendments. Throughout the experiment, the stabilization ratio of available $\mathrm{Pb}$ was approximately $53 \%$. Overall, due to the biological toxicity and non-degradability of $\mathrm{Pb}, \mathrm{Pb}$ stabilization in the contaminated soil mainly depends on its chemical form transformation (Zeng et al., 2017). In this study, the direct adsorption of $\mathrm{Pb}$ onto the amendments was considered an important mechanism for $\mathrm{Pb}$ stabilization in the soil. Simultaneously, adsorption, complexation, surface complexes, and co-precipitation also play an important role (Mavropoulos et al., 2002). However, MFA and $\mathrm{ZE}$ lead to higher soil $\mathrm{pH}$, and whether it results in soil salinisation must further be investigated.

\subsubsection{SOM analysis}

SOM plays a critical role in the heavy metal concentration and morphological transformation because it is a rich source of negative charge (Kabata-Pendias, 2011). A study found that the adsorption of heavy metals on SOM is 6-13 times higher than that on soil minerals (Lair et al., 2007); SOM also improves the soil structure and provides better binding to heavy metal cations (Oste et al., 2002).

Figure 6A presents the concentration profile of SOM. At the beginning of experiment, soil amendments and control did not show considerable differences. However, with the progress of the experiment toward middle and late stages, the differences became larger. The loss of the organic matter in the control soil was higher than that in the amended soils may be because of the leaching effect of deionised water on macromolecular insoluble complexes present in organic 

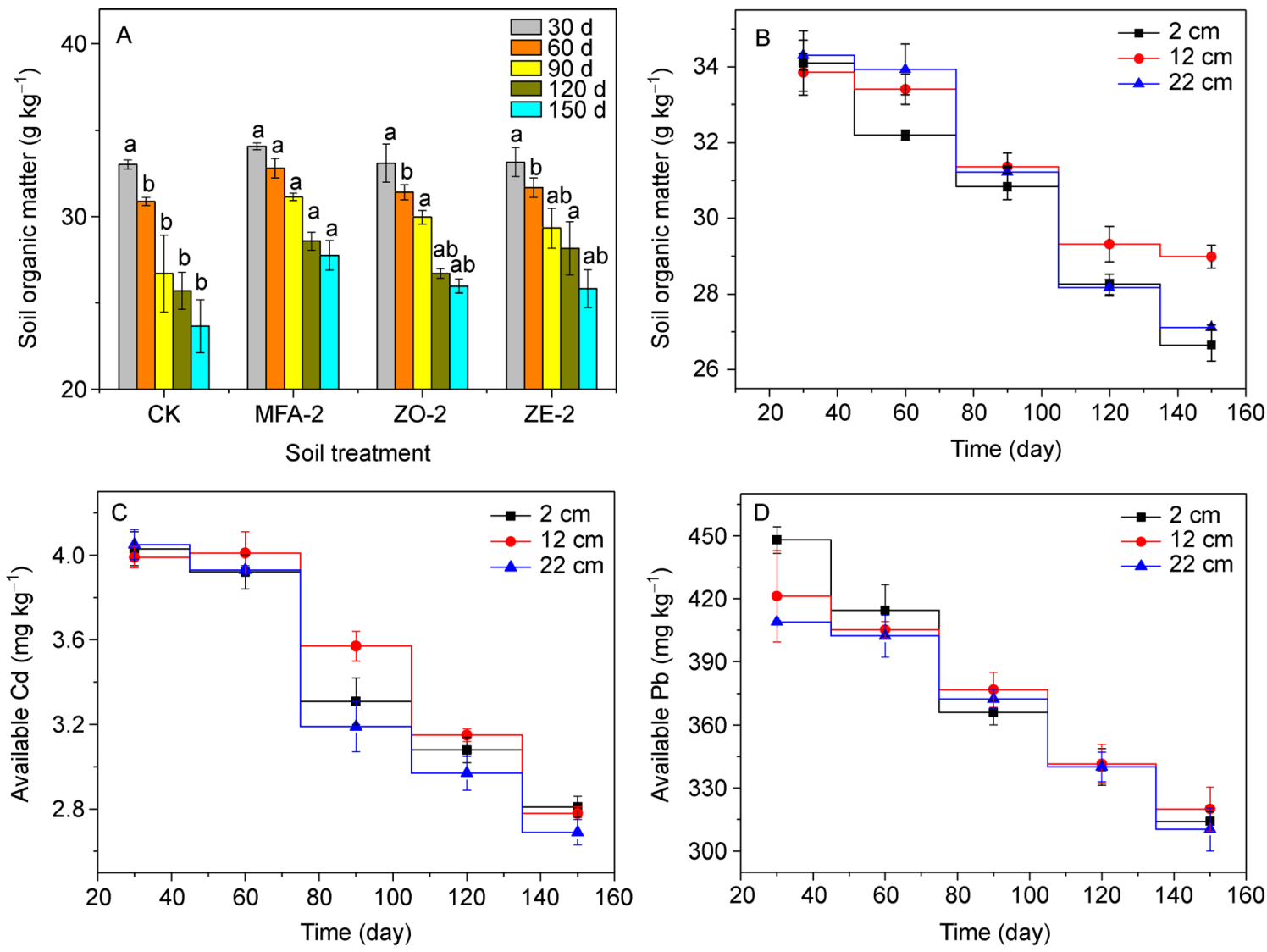

Fig. 6 (A) Concentration of SOM at different times and under different treatments. (B-D) Concentrations of SOM, available Cb, and available $\mathrm{Pd}$ at different soil column depths under the $2 \%$ MFA treatment. The data are the average of the three columns, the error bars represent a standard deviation on either side of the mean. Different lower-case letters indicate significant differences among treatments at $p<0.05$.

components. Furthermore, a long-term suitable temperature leads to an increase in the microbial activity, thereby increasing SOM mineralisation (Davidson and Janssens, 2006). We can infer that the use of soil amendments leads to an increase in the accumulation and sequestration of organic matters. The MFA amendment had the most significant effect on the organic matter due to two reasons: FA modification increased its adsorption capacity and ironaluminum oxide present in FA formed a stronger bond with the organic matter, which improved the adsorption of organic compositions (Oste et al., 2002). The retention mechanism of organic components for heavy metals includes multiple aspects, such as weak physical forces, ion exchange, and the formation of internal spherical complexes (Lair et al., 2007; Ju et al., 2019). Soil amendments accelerated organic matter sequestration, thereby improving the capacity of the organic matter to immobilise heavy metals.

3.3.3 Heavy metals and organic matter at different depths in soil columns

Heavy metal mobilisation in the soil matrix is considered to strongly depend on parameters, such as SOM, DOC, and $\mathrm{pH}$ (Kalbitz and Wennrich, 1998). Figure 6B-D present the distribution profile of $\mathrm{SOM}$, available $\mathrm{Pb}$, and available $\mathrm{Cd}$ with the soil depth. At the beginning of the experiment, the distribution of $\mathrm{SOM}, \mathrm{Pb}$, and $\mathrm{Cd}$ in the soil column was roughly uniform and no obvious differences were observed at three different depths. However, with the proceeding of the experiments, the soil showed a clear concentration gradient across the three different layers: they appeared to mobilise to the lower layer of the soil.

SOM was mainly transported to the middle of the soil column, which could result from an uneven flow of deionised water and the microbial activity in the soil matrix (Lehmann et al., 2018). The migration of available $\mathrm{Cd}$ was similar to that of SOM and it mobilised toward the deeper soil $(2 \mathrm{~cm})$, indicating that $\mathrm{Cd}$ has a strong capacity of migration and mobilisation in the soil environment. In addition to complexing with SOM, pH is an important factor that influences Cd (CruzParedes et al., 2017). Compared with $\mathrm{Cd}, \mathrm{Pb}$ has a lower migration capacity in the soil column, which followed the SOM distribution, indicating that $\mathrm{Pb}$ was substantially influenced by the microbial community and organic matter reduced the toxic 
effect of heavy metals on the microbial activity (Stefanowicz et al., 2020). Thus, SOM is partial to spatially and temporally affect the mobilisation of heavy metals.

\section{Conclusions}

Our investigation showed that the internal structure of FA considerably changed after low-temperature roasting and hydrothermal syntheses. The specific surface area highly enlarged after the modification with $\mathrm{NaOH}$, and the capacity to adsorb heavy metal ions substantially increased. The leaching column experiments showed that MFA and ZE used as soil amendments exhibited positive immobilisation effects on heavy metals.

The leachate and soil composition analyses showed that the input of amendments stimulates an increase in $\mathrm{pH}$, the leaching amount of soluble $\mathrm{Cd}$ and $\mathrm{Pb}$ in the leachate gradually decreases, and $\mathrm{pH}$ is an important factor for heavy metal immobilisation. Moreover, DOC stability is related to the special structure of amendments. Furthermore, DOC stability may be affected through the microbial activity, indicating that long-term experiments are necessary. SOM exhibits a principal effect on the migration and adsorption of heavy metals. The experimental results indicated that the addition of amendments substantially stabilizes the organic matter and improves the soil structure. The study indicated that modified FA as an amendment is an effective remediation measure for the application and management of heavy metal pollution.

\section{Acknowledgments}

This study was supported by the Key Laboratory of Original AgroEnvironmental Pollution Prevention and Control, the Ministry of the Agriculture/Tianjin Key Laboratory of Agro-environment and Safe-Product Open Fund Project (Grant No. 17nybcdgj-2).

\section{References}

Ahmaruzzaman, M., 2010. A review on the utilization of fly ash. Progress in Energy and Combustion Science 36, 327-363.

Alicja, B., Henk, S., Pierre, S., Krystyna, G., Angélique, B., Maxime, P., Hélène, F., 2018. Evolutionary dynamics of quantitative variation in an adaptive trait at the regional scale: the case of zinc hyperaccumulation inlr Arabidopsis halleri. Molecular Ecology 27, 3257-3273.

Andersson, S., Nilsson, S.I., Saetre, P., 2000. Leaching of dissolved organic carbon (DOC) and dissolved organic nitrogen (DON) in mor humus as affected by temperature and $\mathrm{pH}$. Soil Biology \& Biochemistry 32, 1-10.

Antoniadis, V., Alloway, B.J., 2002. The role of dissolved organic carbon in the mobility of $\mathrm{Cd}, \mathrm{Ni}$ and $\mathrm{Zn}$ in sewage sludge-amended soils. Environmental Pollution 117, 515-521.

Astuti, W., Martlani, W., Any Ismawati Khair, N., 2017. Competitive adsorption of $\mathrm{Pb}^{2+}$ and $\mathrm{Zn}^{2+}$ ions from aqueous solutions by modified coal fly ash. In: Engineering International conference
(EIC) 2016. Proceedings of the 5th International Conference on Education, Concept, and Application of Green Technology.

Basta, N.T., McGowen, S.L., 2004. Evaluation of chemical immobilization treatments for reducing heavy metal transport in a smeltercontaminated soil. Environmental Pollution 127, 73-82.

Bradl, H.B., 2004. Adsorption of heavy metal ions on soils and soils constituents. Journal of Colloid and Interface Science 277, 1-18.

Brunner, W., Blaser, P., 1989. Mineralization of soil organic matter and added carbon substrates in two acidic soils with high nonexchangeable aluminum. Journal of Plant Nutrition and Soil Science 152, 367-372.

Christ, M.J., David, M.B., 1996. Temperature and moisture effects on the production of dissolved organic carbon in a Spodosol. Soil Biology \& Biochemistry 28, 1191-1199.

Cruz-Paredes, C., Wallander, H., Kjǿller, R., Rousk, J., 2017. Using community trait-distributions to assign microbial responses to $\mathrm{pH}$ changes and $\mathrm{Cd}$ in forest soils treated with wood ash. Soil Biology \& Biochemistry 112, 153-164.

Davidson, E.A., Janssens, I.A., 2006. Temperature sensitivity of soil carbon decomposition and feedbacks to climate change. Nature 440, 165-173.

Deng, X., Qi, L.Q., Zhang, Y., 2018. Experimental study on adsorption of hexavalent chromium with microwave-assisted alkali modified fly ash. Water, Air, and Soil Pollution 229, 18 (2018).

Duan, C., Fang, L., Yang, C., Chen, W., Cui, Y., Li, S., 2018. Reveal the response of enzyme activities to heavy metals through in situ zymography. Ecotoxicology and Environmental Safety 156, 106115.

Fest, E.P.M.J., Temminghoff, E.J.M., Comans, R.N.J., van Riemsdijk, W.H., 2008. Partitioning of organic matter and heavy metals in a sandy soil: Effects of extracting solution, solid to liquid ratio and pH. Geoderma 146, 66-74.

Griffin, R.A., Au, A.K., 1977. Lead adsorption by montmorillonite using a competitive langmuir equation 1 . Soil Science Society of America Journal 41, 880-882.

Houben, D., Pircar, J., Sonnet, P., 2012. Heavy metal immobilization by cost-effective amendments in a contaminated soil: Effects on metal leaching and phytoavailability. Journal of Geochemical Exploration 123, 87-94.

Huang, J., Yuan, F., Zeng, G., Li, X., Gu, Y., Shi, L., Liu, W., Shi, Y., 2017. Influence of $\mathrm{pH}$ on heavy metal speciation and removal from wastewater using micellar-enhanced ultrafiltration. Chemosphere 173, 199-206.

Huang, X., Zhao, H., Hu, X., Liu, F., Wang, L., Zhao, X., Gao, P., Ji, P., 2020b. Optimization of preparation technology for modified coal fly ash and its adsorption properties for $\mathrm{Cd}^{2}$. Journal of Hazardous Materials 392, 122461.

Huang, X., Zhao, H., Zhang, G., Li, J., Yang, Y., Ji, P., 2020a. Potential of removing $\mathrm{Cd}(\mathrm{II})$ and $\mathrm{Pb}(\mathrm{II})$ from contaminated water using a newly modified fly ash. Chemosphere 242, 125148.

Huang, Y.F., Chen, G.F., Xiong, L.M., Huang, Y.Y., 2016. Current situation of heavy metal pollution in farm land soil and phytoremediation application. Asian Agricultural Research 8, 22-24.

Jaarsveld, J.G.S.V., Deventer, J.S.J.V., Schwartzman, A., 1999. The potential use of geopolymeric materials to immobilise toxic metals: Part II. Material and leaching characteristics. Minerals Engineering 
$12,75-91$.

Ju, W., Liu, L., Fang, L., Cui, Y., Duan, C., Wu, H., 2019. Impact of coinoculation with plant-growth-promoting rhizobacteria and rhizobium on the biochemical responses of alfalfa-soil system in copper contaminated soil. Ecotoxicology and Environmental Safety 167, 218-226.

Kabata-Pendias, A., 2011. Trace Elements in Soils and Plants. 4th edition. USA: CRC Press/Taylor \& Francis Group.

Kalbitz, K., Wennrich, R., 1998. Mobilization of heavy metals and arsenic in polluted wetland soils and its dependence on dissolved organic matter. Science of the Total Environment 209, 27-39.

Khan, S., Cao, Q., Zheng, Y.M., Huang, Y.Z., Zhu, Y.G., 2008. Health risks of heavy metals in contaminated soils and food crops irrigated with wastewater in Beijing, China. Environmental Pollution 152, 686-692.

Lair, G.J., Gerzabek, M.H., Haberhauer, G., 2007. Sorption of heavy metals on organic and inorganic soil constituents. Environmental Chemistry Letters 5, 23-27.

Lee, H., Ha, H.S., Lee, C.H., Lee, Y.B., Kim, P.J., 2006. Fly ash effect on improving soil properties and rice productivity in Korean paddy soils. Bioresource Technology 97, 1490-1497.

Lee, S.B., Lee, Y.B., Lee, C.H., Hong, C.O., Kim, P.J., Yu, C., 2008. Characteristics of boron accumulation by fly ash application in paddy soil. Bioresource Technology 99, 5928-5932.

Leelarungroj, K., Likitlersuang, S., Chompoorat, T., Janjaroen, D., 2018. Leaching mechanisms of heavy metals from fly ash stabilised soils. Waste Management \& Research 36, 616-623.

Lehmann, K., Schaefer, S., Babin, D., Koehne, J., Maximilian, S., 2018. Selective transport and retention of organic matter and bacteria shapes initial pedogenesis in artificial soil-A two-layer column study. Geoderma 325, 37-48.

Li, Z., Li, M., Wang, Z., Liu, X., 2020. Coadsorption of $\mathrm{Cu}(\mathrm{II})$ and tylosin/sulfamethoxazole on biochar stabilized by nano-hydroxyapatite in aqueous environment. Chemical Engineering Journal 381, 122785.

Lin, J., He, F., Su, B., Sun, M., Owens, G., Chen, Z., 2019. The stabilizing mechanism of cadmium in contaminated soil using green synthesized iron oxide nanoparticles under long-term incubation. Journal of Hazardous Materials 379, 120832.

Mavropoulos, E., Rossi, A.M., Costa, A.M., Perez, C.A.C., Moreira, J. C., Saldanha, M., 2002. Studies on the mechanisms of lead immobilization by hydroxyapatite. Environmental Science \& Technology 36, 1625-1629.

Morel, B., Durand, P., Jaffrezic, A., Gruau, G., Molenat, J., 2009. Sources of dissolved organic carbon during stormflow in a headwater agricultural catchment. Hydrological Processes 23 2888-2901.

Mukherjee, I., Singh, U.K., Singh, R.P., Anshumali, Kumari, D., Jha, P. K., Mehta, P., 2020. Characterization of heavy metal pollution in an anthropogenically and geologically influenced semi-arid region of east India and assessment of ecological and human health risks. Science of the Total Environment 705, 135801

Nag, M., Saffarzadeh, A., Nomichi, T., Shimaoka, T., Nakayama, H., 2020. Enhanced $\mathrm{Pb}$ and $\mathrm{Zn}$ stabilization in municipal solid waste incineration fly ash using waste fishbone hydroxyapatite. Waste Management (New York, N.Y.) 118, 281-290.
Nayak, A.K., Raja, R., Rao, K.S., Shukla, A.K., Mohanty, S., Shahid, M., Tripathi, R., Panda, B.B., Bhattacharyya, P., Kumar, A., Lal, B., Sethi, S.K., Puri, C., Nayak, D., Swain, C.K., 2015. Effect of fly ash application on soil microbial response and heavy metal accumulation in soil and rice plant. Ecotoxicology and Environmental Safety 114, 257-262.

Oste, L.A., Temminghoff, E.J.M., van Riemsdijk, W.H., 2002. Solidsolution partitioning of organic matter in soils as influenced by an increase in $\mathrm{pH}$ or $\mathrm{Ca}$ concentration. Environmental Science \& Technology 36, 208-214.

Pani, A., Singh, S.P., 2019. In-situ stabilization of sedimented ash deposit by partial penetrating chemical columns. Journal of Environmental Management 231, 21-32.

Qi, L.Q., Teng, F., Deng, X., Zhang, Y.J., Zhong, X.Y., 2019. Experimental study on adsorption of $\mathrm{Hg}$ (II) with microwaveassisted alkali-modified fly ash. Powder Technology 351, 153-158.

Semple, K.T., Doick, K.J., Jones, K.C., Burauel, P., Craven, A., Harms, $\mathrm{H}$., 2004. Defining bioavailability and bioaccessibility of contaminated soil and sediment is complicated. Environmental Science \& Technology 38, 228A-231A.

Shao, D., Zhan, Y., Zhou, W., Zhu, L., 2016. Current status and temporal trend of heavy metals in farmland soil of the Yangtze River Delta Region: Field survey and meta-analysis. Environmental Pollution. 219, 329-336.

Smolyakov, B.S., Ryzhikh, A.P., Bortnikova, S.B., Saeva, O.P., Chernova, N.Y., 2010. Behavior of metals (Cu, $\mathrm{Zn}$ and $\mathrm{Cd}$ ) in the initial stage of water system contamination: Effect of $\mathrm{pH}$ and suspended particles. Applied Geochemistry 25, 1153-1161.

Sneddon, I.R., Orueetxebarria, M., Hodson, M.E., Schofield, P.F., Valsami-Jones, E., 2006. Use of bone meal amendments to immobilise $\mathrm{Pb}, \mathrm{Zn}$ and $\mathrm{Cd}$ in soil: A leaching column study. Environmental Pollution 144, 816-825.

Stefanowicz, A.M., Kapusta, P., Zubek, S., Stanek, M., Woch, M.W., 2020. Soil organic matter prevails over heavy metal pollution and vegetation as a factor shaping soil microbial communities at historical Zn-Pb mining sites. Chemosphere 240, 124922.

Stötzel, C., Müller, F.A., Reinert, F., Niederdraenk, F., Barralet, J.E., Gbureck, U., 2009. Ion adsorption behaviour of hydroxyapatite with different crystallinities. Colloids and Surfaces B: Biointerfaces 74, 91-95.

Terzano, R., Spagnuolo, M., Medici, L., Vekemans, B., Vincze, L., Janssens, K., Ruggiero, P., 2005. Copper stabilization by zeolite synthesis in polluted soils treated with coal fly ash. Environmental Science \& Technology 39, 6280-6287.

Tian, H., Fang, L., Duan, C., Wang, Y., Wu, H., 2018. Dominant factor affecting $\mathrm{Pb}$ speciation and the leaching risk among land-use types around $\mathrm{Pb}-\mathrm{Zn}$ mine. Geoderma 326, 123-132.

Titeux, H., Delvaux, B., 2009. Experimental study of DOC, nutrients and metals release from forest floors developed under beech (Fagus sylvatica L.) on a Cambisol and a Podzol. Geoderma 148, 291-298.

Wang, Y., Zheng, K., Zhan, W., Huang, L., Liu, Y., Li, T., Yang, Z., Liao, Q., Chen, R., Zhang, C., Wang, Z., 2021. Highly effective stabilization of $\mathrm{Cd}$ and $\mathrm{Cu}$ in two different soils and improvement of soil properties by multiple-modified biochar. Ecotoxicology and Environmental Safety 207, 111294 
Wu, X.W., Ma, H.W., Zhang, L.T., Wang, F.J., 2012. Adsorption properties and mechanism of mesoporous adsorbents prepared with fly ash for removal of $\mathrm{Cu}(\mathrm{II})$ in aqueous solution. Applied Surface Science 261, 902-907.

Xu, J.Z., Zhou, Y.L., Chang, Q., Qu, H.Q., 2006. Study on the factors of affecting the immobilization of heavy metals in fly ash-based geopolymers. Materials Letters 60, 820-822.

Xu, M.M., Zhao, Z.J., Song, Y.R., Li, J., You, Y., Li, J., 2020. Evaluation of ferrihydrite-humic acid coprecipitate as amendment to remediate a Cd- and Pb-contaminated soil. Geoderma 361, 114131.

Zeng, F., Ali, S., Zhang, H., Ouyang, Y., Qiu, B., Wu, F., Zhang, G.,
2011. The influence of $\mathrm{pH}$ and organic matter content in paddy soil on heavy metal availability and their uptake by rice plants. Environmental Pollution 159, 84-91.

Zeng, G., Wan, J., Huang, D., Hu, L., Huang, C., Cheng, M., Xue, W., Gong, X., Wang, R., Jiang, D., 2017. Precipitation, adsorption and rhizosphere effect: The mechanisms for Phosphate-induced $\mathrm{Pb}$ immobilization in soils-A review. Journal of Hazardous Materials 339, 354-367.

Zhao, F.J., Ma, Y., Zhu, Y.G., Tang, Z., McGrath, S.P., 2015. Soil contamination in China: current status and mitigation strategies. Environmental Science \& Technology 49, 750-759. 